\title{
Accumulation of Poly-hydroxy-butyric Acid (PHB) by Bacillus Strain Isolated from Paddy Field of Kathmandu University Premises
}

\author{
Deepak Upreti, Naresh Prasad Sapkota, Bibek Aryal, Sangita Shakya* \\ Department of Biotechnology, Kathmandu University, Dhulikhel, Nepal
}

\begin{abstract}
In this study, the effect of applying nutrient limitation on the production of Poly-hydro-oxy-butyric acid (PHB) from soil bacteria was examined. PHB is a biodegradable polymer which provides a reserve of carbon and energy. PHB was extracted by chloroform dispersion method. The amount of synthesized PHB was determined as crotonic acid by spectrophotometry. We found that Nitrogen limiting condition stimulated PHB accumulation. The highest level of PHB accumulation was observed in DNB-6 strain which accumulated $31 \%$ of the dry mass at $20 \%$ glucose concentration. The probabilistic identification of bacteria by PIBwin software version 1.9.2 showed that the strain DNB-6 was close in nature to Bacillus cereus.
\end{abstract}

Keywords: Polyhydrooxybutyrate, Cell dry weight, Nutrient limitation, biodegradable, bioplastic.

*Corresponding author

Email: sangita@ku.edu.np

\section{Introduction}

Poly-hydro-oxy-butyric acid (PHB) is a member of a polymer belonging to a group polyhydroalkanoate (PHA). A wide variety of prokaryotic organisms have been shown to accumulate this polymer, including numerous heterotrophic and autotrophic aerobic bacteria, photosynthetic anaerobic bacteria, gliding bacteria, actinomycetes species, cyanobacteria [1].

PHB is a biodegradable thermoplastic which provides a reserve of carbon and energy and accumulates as intracellular granules when grown under nutrient limiting conditions [2]. Three distinct enzymatic reactions involved in the PHB biosynthetic pathway. The initial reaction involves condensation of two acetyl-COA molecules to form acetoacetylCoA, which is catalyzed by $B-$ ketothiolase encoded by $p h b A$. This step is followed by the reduction of acetoacetyl-CoA by an NADPH- dependent acetoacetyl-COA dehydrogenase encoded by $p h b B$. Then, the (R)-3- Hydroxybutyrl- COA monomers are polymerized into PHB by PHB synthase encoded by phbC (Figure 1) [3].

The synthetic plastics are made from petrochemicals which are not renewable. They do not readily biodegrade and often the collection and transport of this waste is difficult and expensive. Due to the nonbiodegradable characteristics of petrochemicalsderived plastic materials much interest has been created in the development of biodegradable plastics. Biodegradation is chemical degradation of materials brought about by the action of naturally occurring microorganisms such as bacteria and algae [4].

Biodegradable plastics produced from renewable sources are considered a potential substitute for conventional petrochemical plastics because of their biodegradability and non-toxicity characteristics $[1,5-$ 7]. PHB is one of the potential raw materials for producing biodegradable plastic. The PHB production capacities of bacteria have been investigated for possible application in industry. However, the use of PHB in industrial applications has been hampered mainly by their high production cost compared to petrochemical-based polymers $[8,9]$. The condition for bacterial PHB production can be met in soil, due to its heterogeneous nature. It may become a limiting factor for bacterial growth especially in some nitrogen poor (carbon-rich) sites. Soil Bacillus species have been shown to accumulate PHB during the sporulation of bacterial growth. PHB production by the isolate has been favoured by the glucose concentration [10].
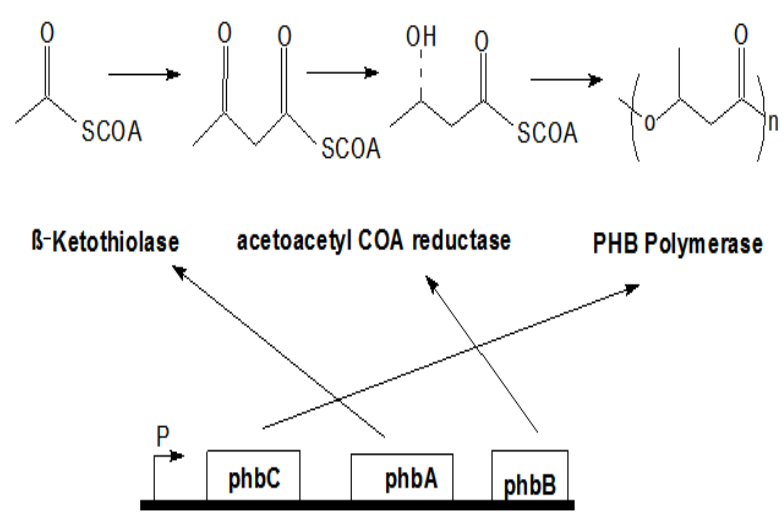

Figure $\mathrm{l}$ : Biosynthetic pathway for $\mathrm{P}(3 \mathrm{HB}) . \mathrm{P}(3 \mathrm{HB})$ is synthesized in a three step pathway by the successive action of B-ketoacetyl-CoA thiolase ( $\mathrm{PhbA}$ ), acetoacetyl $\mathrm{CoA}$ reductase (phbB), and $\mathrm{P}(3 \mathrm{HB})$ polvmerase (PhbC). The three enzymes are coded by the genes of the phbCAB operon. $A$ promoter upstream of phbC transcribes the complete operon. 
This study makes an effort to evaluate the PHBproducing efficiency of Bacillus species isolated from soil, located in the paddy field of Kathmandu University premises under nutrient limited conditions. The polymer has been extracted from a selected Bacillus species strain and characterized partially.

\section{Materials and Methods}

\section{Isolation and purification of soil Bacteria}

The soil sample for the isolation of bacteria was collected during the months of March to May. Soil Samples were collected from five different areas of paddy field of Kathmandu University premises. Fifteen soil isolates were named as (DNB-1 - DNB-15) and further screened randomly to check their PHBproducing efficiency. Each gram of the sample was suspended in $9 \mathrm{ml}$ of sterile distilled water and shaken vigorously for $2 \mathrm{~min}$. The sample was heated at $80{ }^{\circ} \mathrm{C}$ for 10 minutes in water bath. After heating, dilution of $10^{-3}, 10^{-4}, 10^{-5}, 10^{-6} \mathrm{~g} / \mathrm{ml}$ were prepared from the soil suspension for plate counts and spread on Nutrient Agar medium. After incubation at $30^{\circ} \mathrm{C}$ for 24- 48 hours, serially diluted plates were picked up and examined microscopically. As standard practice, plates having 30-300 colonies were chosen for isolating the single bacterial colony.

The spore morphology, gram staining, motility and several biochemical tests were carried out to characterize the bacteria. The isolate was identified on the basis of comparison of these characters with those described in Bergey's Manual of Determinative bacteriology [11].

\section{Screening for PHB production}

To test the production of $\mathrm{PHB}$, seed culture of isolated colonies were grown in $10 \mathrm{ml}$ Nutrient broth and incubated for 24 hours at $30^{\circ} \mathrm{C}$. Later, the seed culture was transferred to $50 \mathrm{ml}$ in $250 \mathrm{ml}$ Erlenmeyer flasks with a $2 \%(\mathrm{v} / \mathrm{v})$ inoculums and incubated at 30 ${ }^{\circ} \mathrm{C}$ with vigorous orbital shaking at $150 \mathrm{rpm}$. The culture was grown to a stationary phase and the cultures were examined by fluorescence microscopy after staining with nile red. It has been proved that nile red is an excellent vital stain for the detection of intracellular lipids. The cells were flame-fixed on slide glass, then a drop of $0.1 \mu \mathrm{g} / \mathrm{ml}$ nile red solution was added to the smear. After being heated over a flame for 1 second, the smear was covered with a cover-glass and examined under the fluorescence microscope. Nile red staining gives strong fluorescence [12].

\section{PHB Analysis}

Dry cell mass was treated with a dispersion containing chloroform and $80 \%$ Sodium hypochlorite in water at a 3:1 ratio. The mixture was then incubated at $30^{\circ} \mathrm{C}$ for 1 hour and then centrifuged at 10,000 $\mathrm{g}$ for 10 minutes. Three different layers were formed. The upper phase was a hypochlorite solution, the middle phase contained non-PHB cell material and undisrupted cells, and the bottom phase was chloroform containing PHB. The upper phase was removed first with a pipette. The chloroform layer was also drawn using a pipette. The PHB was then extracted from the chloroform layer by slowly introducing the chloroform into ten volumes of ice cold methanol with continuous stirring.

\section{Chemical Determination of PHB}

Chloroform extract was dried at $40^{\circ} \mathrm{C}$ and $10 \mathrm{ml}$ of concentrated sulphuric acid was added. Then they were heated at $100{ }^{\circ} \mathrm{C}$ in a water bath for $20 \mathrm{~min}$. After cooling, the sample was transferred to a silica cuvette and the absorbance at wavelength of $235 \mathrm{~nm}$ is measured against a sulphuric acid as a blank.

\section{Results}

Of the fifteen samples evaluated for PHB production, DNB-6 isolate accumulated the maximum PHB $(31.91 \%)$ of dry cell weight. The isolate was identified as a member of genus Bacillus when biochemical and morphological test was matched to Bergey's Manual of Determinative Bacteriology. Citrate utilization, growth pattern, carbohydrate utilization and number of other tests as summarized in the (Table 1, Figure 2). When the results of these tests were inserted in PIBwin software version 1.9.2, the strain DNB-6 was identified to close in nature to Bacillus cereus with ID score of 0.76 .

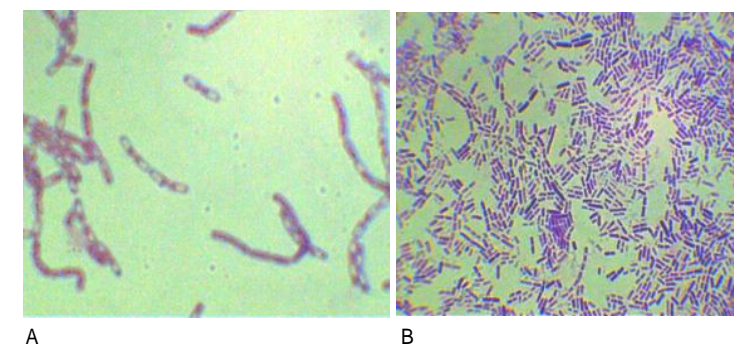

Figure 2 A, B: Gram staining and Endospore test. A: Gram staining of DNB-6, B: Endospore of strain DNB-6.

\section{Growth curve analysis}

The growth curve was plotted under nitrogen deficient media (NDM), phosphate deficient media (PHDM), and potassium deficient media (PDM), sulfur deficient media (SDM) (Figure 3). 
Table 1: PBB production and characteristics of DNB-6

\begin{tabular}{lc}
\hline PHB production and characteristics of DNB-6 strain \\
\hline PHB \% dry weight & $31.96 \%$ \\
Spore formation & central \\
Colony type & circular \\
Gram staining & Positive, rod \\
Casein hydrolysis & positive \\
Starch hydrolysis & positive \\
Motility test & positive \\
Nitrate reduction & positive \\
Catalase test & positive \\
Oxidative fermentation & positive \\
\hline
\end{tabular}

It was observed that the DNB-6 showed good growth at nitrogen deficient media (Figure 3). The growth curve was plotted up to 72 hours in 6 hours interval of time at $20 \%$ glucose concentration (Figure 3 ).

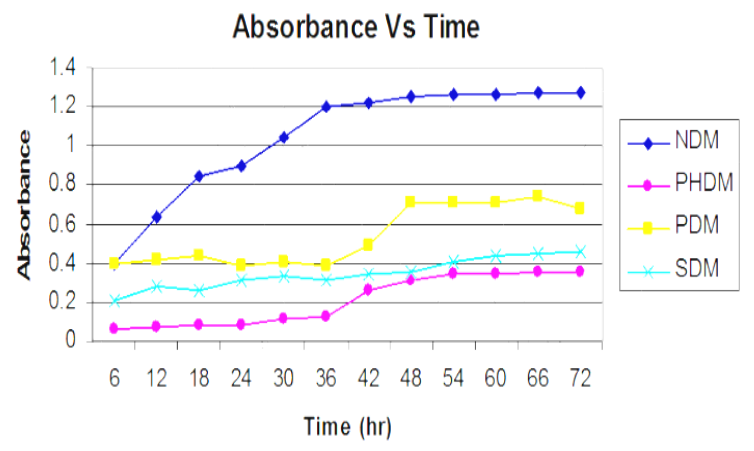

Figure 3: Comparison of Growth curve of DNB-6 under nitrogen deficient media (NDM), Phosphate deficient media (PHDM), Potassium deficient media (PDM) and sulfur deficient media (SDM) at 20\% Glucose concentration.

\section{PHB yield analysis}

Production of PHB was maximum at 48 hours (Figure 4) when DNB-6 strain was subjected to nitrogen limiting at $20 \%$ glucose concentration.

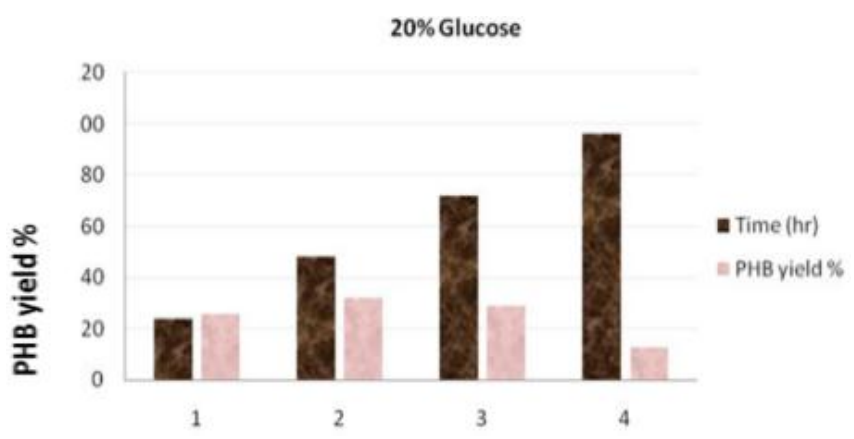

Figure 4: Time profile of PHB accumulation under nitrogen deficient media at $20 \%$ Glucose concentration (1: $24 \mathrm{hr}, 2$ : $48 \mathrm{hr}, 3$ : $72 \mathrm{hr}$ and 4: 96hr).

The intensity of fluorescence was checked at different time interval under nitrogen limitation by fluorescence microscope (Figure 5A, 5B, 5C, 5D). Time profile of growth and PHB production accumulation have indicated that maximum $\mathrm{PHB}$ production during starting of stationary phase and degraded during late stationary phase.
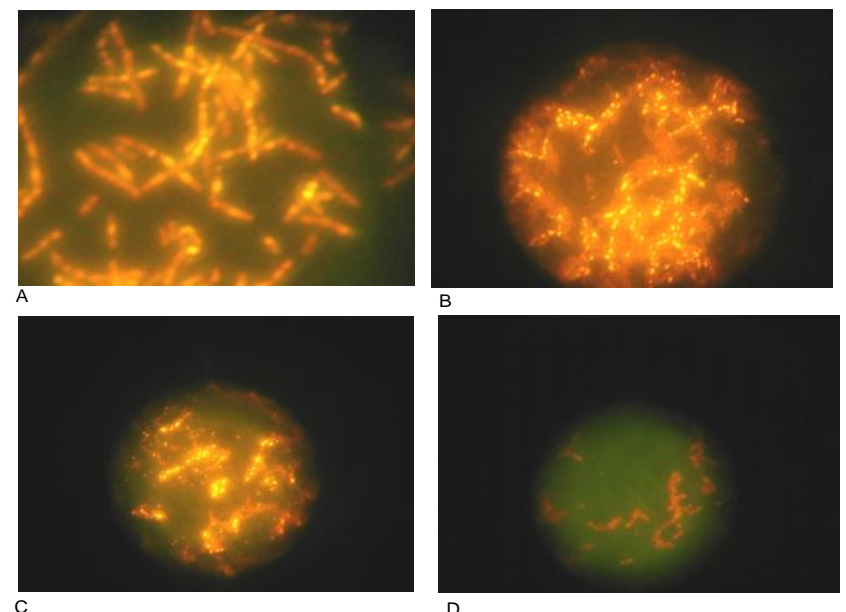

Figure 5: PHB intensity under fluorescent microscope. A: PHB intensity at 24 hours of strain DNB-6, B: PHB intensity at 48 hours of strain DNB-6, C: PHB intensity at 72 hours strain DNB-6 D: PHB intensity at 96 hours of Strain DNB-6.

\section{Discussion}

Growth curve analysis showed that PHB was a growth associated product and its accumulation is significantly increased when all cultures reached from exponential phase to till-stationary phase. Different intensity of PHB obtained at different time also coincided with the PHB yield at different time. The analysis of PHB yield was carried out in nitrogen deficient media because the growth curve as well as PHB intensity observed under this condition was better than in other conditions. The bacteria were harvested at 24 hours, 48 hours, 72 hours and 96 hours. The yield percentage of PHB was maximum at 48 hours at $20 \%$ glucose concentration. This reflected that by this time the bacteria had already entered the stationary phase. It was observed that the bacteria start accumulating PHB granules in its stationary phase (Anupam et al., 1999). This high yield of polymer could be because of using glucose as the carbon source. Bacillus cereus when grown on structurally unrelated carbon such as fructose, sucrose and gluconate has produced interesting other polymer beside PHB [13].

There was variability in PHB accumulation at different time profile. The highest PHB producing efficiency was found in isolate DNB-6. The maximum PHB yield was $31.91 \%$ of dry weight under nitrogen deficient media at $20 \%$ glucose concentration. The recovery process was carried by chloroform dispersion method. The PHB yield was parallel to the bacterial growth.

In conclusion, soil bacterial isolate found were capable of accumulating PHB as an energy material. 
The present study showed that the maximum PHB production was under nitrogen limitation condition which agrees well with other study that suggests PHB production was maximum under nutrient limiting condition.

\section{Acknowledgements}

This research was supported by Kathmandu University, Department of Biotechnology.

\section{Author Contributions}

Assistant Prof. Sangita Shakya designed and supervised the project. Deepak Upreti prepared the manuscript. Deepak Upreti, Naresh Prasad Sapkota and Bibek Aryal share the equal amount of contributions in this work.

\section{References}

1. Lara LM, Huisman GW: Metabolic Engineering of Poly (3-Hydroxyalkanoates): From DNA to Plastic. Microbiol Mol Biol Rev 1999, 63: 21-53.

2. Choi J, Lee SY: Process analysis and economic evaluation for Poly (3-hydroxybutyrate) production by fermentation. Bioprocess Engineering 1997, 17: 335-342.

3. Stockdale H, Ribbons DW, Dawes EA: Occurrence of Poly-B-Hydroxybutyrate in the Azotobacteriaceae. J Bacteriol 1968, 95: 1798-1803.

4. Kyrikou I, Briassoulis, D: Biodegradation of Agriculture Plastic Films: A Critical Review. J Polym Environ 2007, 15: 125-150.

5. Wang F, Lee YL: Poly (3-Hydroxybutyrate) production with High Productivity and High Polymer Content by a Fed-Batch Culture of Alcaligenes latus under Nitrogen Limitation. Appl Environ Microbiol 1997, 63: 3703-3706.

6. Singh M, Patel S, Kalia V: Bacillus Subtilis as potential producer for polyhydroxyalkanoates. Microb Cell Fact 2009, 8: 38.

7. Ojumu TV, Yu J, Solomon BO: Production of Polyhydroxyalkanoates, a bacterial biodegradable polymer .A J Biotechnol 2004, 3: 18-24.

8. Byrom D: Polymer synthesis by microorganisms: technology and economics. Trends Biotechnol 1987, 5: 246-250.

9. Chio J, Lee Y: Factors affecting the economics of Polyhydroxyalkanotate production by bacterial fermentation. Appl Microbiol Biotechnol 1999, 51: 1321.

10. Anupam M, Banerjee R, Paul AK: Accumulation of Poly (3-hydroxybutyric Acid) by some soil streptomyces. Curr Microbiol 1999, 39: 153-158.

11. Holt JG: Bergey's Manual of Determinative Bacteriology. Lippincott Williams and Wilkins Baltimore; 1994.

12. Greenspan P, Mayer EP, Fowler SD. Nile red: Selective Fluorescent stain for intracellular lipid droplets. J Cell Biol 1985, 100: 965-973.
13. Stockdale H, Ribbons DW, Dawes EA: Occurrence of Poly-ß-Hydroxybutyrate in the Azotobacteriaceae. J Bacteriol 1968, 95: 1798-1803 